\title{
Abruptio placenta and its maternal and fetal outcome
}

\author{
Ritu Mishra ${ }^{1}$, Aditya Prakash Misra ${ }^{2 *}$
}

\author{
${ }^{1}$ Department of Obstetrics and Gynecology, Rama Medical College, Hospital and Research Center, Mandhana, \\ Kanpur, Uttar Pradesh, India \\ ${ }^{2}$ Department of Radiodiagnosis, Rama Medical College, Hospital and Research Center, Mandhana, Kanpur, Uttar \\ Pradesh, India
}

Received: 16 April 2019

Accepted: 06 July 2019

\section{*Correspondence:}

Dr. Aditya Prakash Misra,

E-mail: saggimishra@hotmail.com

Copyright: () the author(s), publisher and licensee Medip Academy. This is an open-access article distributed under the terms of the Creative Commons Attribution Non-Commercial License, which permits unrestricted non-commercial use, distribution, and reproduction in any medium, provided the original work is properly cited.

\begin{abstract}
Background: Abruptio placenta is one of the common cause of antepartum haemorrhage and is defined as premature separation of normally implanted placenta. It is more common in second half of pregnancy. Abruptio placenta is serious complication of pregnancy and causes high maternal and neonatal morbidity and mortality.

Methods: This retrospective study of abruptio and its maternal and perinatal outcome was carried out between July 2016 and October 2017 at Rama Medical College Hospital and research centre.

Results: Incidence of Abruptio placenta is $1.6 \%$. It is most common in the women of age group 30-35 years. $75 \%$ of cases were associated with severe pre-eclampsia. Live births were $75 \%$ while stillbirths were $25 \%$. PPH occurred in $30 \%$ of cases. DIC accounts for $25 \%$ of the complication.

Conclusions: Abruptio placenta is life threatening complication of pregnancy and it is associated with poor maternal and fetal outcome if not managed appropriately. Hence early diagnosis and prompt resuscitative measures would prevent both perinatal and maternal mortality and morbidity.
\end{abstract}

Keywords: Abruptio placenta, Maternal, Mortality, Morbidity, Neonatal, Pre-eclampsia

\section{INTRODUCTION}

Placental abruption is the most common cause of antepartum haemorrhage and is defined as premature separation of normally implanted placenta. ${ }^{1}$ Placental abruption occurs when there is a compromise of the vascular structures supporting the placenta. In other words, the vascular networks connecting the uterine lining and the maternal side of the placenta are torn away. These vascular structures deliver oxygen and nutrients to the fetus. Disruption of the vascular network may occur when the vascular structures are compromised because of hypertension or substance use or by conditions that causes stretching the uterus. The uterus is a muscle and is elastic whereas the placenta is less elastic than the uterus. Therefore, when the uterine tissue stretches suddenly, the placenta remains stable and the vascular structure connecting the uterine wall to the placenta tear away., 2,3 Placental abruption is one of the causes of vaginal bleeding in the second half of pregnancy. A focused history and physical examination is critical to differentiate placental abruption from other causes of vaginal bleeding. Placental abruption is a potentially lifethreatening situation. Therefore, accurate assessment of the patient and according management is very important to prevent a potentially poor outcome. The exact etiology of placental abruption is unknown. However, a number of factors are associated with its occurrence. Risk factors 
can be thought of in four groups: health history, past obstetrical events, current pregnancy, and unexpected trauma. Factors that increase the risk of placental abruption includes smoking, cocaine use during pregnancy, maternal age over 35 years, hypertension, and placental abruption in a prior pregnancy. Conditions specific to the current pregnancy which may precipitate placental abruption are multiple gestation pregnancies, polyhydramnios, preeclampsia, diabetes, sudden uterine decompression, and short umbilical cord. Finally, trauma to the abdomen such as a motor vehicle accident, fall or violence resulting in a blow to the abdomen may lead to placental abruption. Abruption is a significant cause of maternal and perinatal morbidity and mortality. Placental abruption may be total or partial, causing pain and vaginal bleeding-which are the hallmarks of placental abruption. Abruptio placenta is the major cause of haemorrhagic shock, DIC, renal failure and neonatal complications include hypoxia, anemia, growth restriction, prematurity, neurodevelopmental problems and premature death. Hypertensive disorder of pregnancy is associated with $2.5 \%$ to $17.9 \%$ of placental separation. ${ }^{4}$ Maternal and fetal survival depends on early diagnosis and intervention. The history begins with a review of the prenatal course, especially placental location on prior sonograms and if there is a history of placental abruption in previous pregnancies. History of smoking and potential trauma especially in the abdominal area is important. Assessment of the patient can provide very important clue for diagnosing onset of abruptio placenta. The physical examination includes palpation of the uterus for tenderness, consistency, and frequency and duration of uterine contractions. The vaginal area is inspected for the presence of bleeding. Digital examination of the cervix should be delayed until a sonogram is obtained for placental localization and to rule out a placenta previa. If bleeding is present, the quantity and characteristic of the blood, as well as the presence of clots is evaluated. However, the absence of vaginal bleeding does not eliminate the diagnosis of placental abruption.

\section{METHODS}

This is a retrospective study conducted at Rama Medical College Hospital and research centre, Kanpur, India from July 2016 to October 2017. Total number of deliveries from July 2016 to October 2017 were 3000. Total number of abruptio placenta cases from July 2016 to October 2017 were 50. From case sheets, details of the patient like age, parity and maternal high-risk factors were collected. Patients with other causes of APH like placenta previa and other extra placental causes were excluded. All study patients underwent a complete obstetrical examination and clinical workup including history, general physical examination and abdominal and pelvic examination. Detailed obstetric history was obtained and maternal high- risk factors like PIH, GDM, polyhydramnios was noted. As $95 \%$ patients were admitted as emergencies, placental abruption was suspected depending on clinical features like vaginal bleeding, uterine tenderness, hypertonic uterus and diagnosis was confirmed by retroplacental clots. After initial resuscitation, mode of delivery was decided depending upon state of mother and fetus. Relevant blood investigations were done. Ultrasound for fetal well-being was done. Diagnosis was confirmed by the presence of retroplacental clots which was used to estimate the amount of bleeding and severity of abruption. Patients were managed according to the fetal and maternal conditions. Accordingly, results were analysed. Maternal complications studied were $\mathrm{PPH}$, DIC, ARF, shock, pulmonary edema and infections. Fetal outcome were studied in the form of perinatal mortality (still births and neonatal deaths), prematurity and admission to the neonatal care unit.

\section{RESULTS}

Maximum no. of cases (40\%) of abruptio placenta were between 30 to 35 years. Increase maternal age is risk factor for abruptio placenta (Table 1). Maximun number of cases was Gravida 2 (35\%) (Table 2). Chances of abruptio plaenta increase with increase parity. Patients who had severe preeclampsia have maximum rate of occurance of abruption (75\%) (Table 3). Most of them were associated with anemia and PIH. $10 \%$ patients with eclampsia had abruptio placenta. Even normotensive groups had abruption which was about $15 \%$. $75 \%$ had live birth, $25 \%$ had still born baby (Table 4). Among them 5 died in early neonatal period due to prematurity. Fetal complications included hypoxia, anemia, growth restriction, prematurity, neurodevelopmental problems, prematurity and fetal death. Maternal complications associated with abruption were Postpartum Haemorrhage (PPH) (30\%), Disseminated Intravascular Coagulation (DIC) $(25 \%)$, Acute renal failure (ARF) (13\%), Shock (12\%). $10 \%$ patients had infections and $10 \%$ suffered from other complication (Table 5).

Table 1: Association with age.

\begin{tabular}{|l|l|}
\hline Age & Percentage \\
\hline $20-25$ years & $10 \%$ \\
\hline $25-30$ years & $30 \%$ \\
\hline $30-35$ years & $40 \%$ \\
\hline$>35$ years & $20 \%$ \\
\hline
\end{tabular}

Maximum number of cases $(40 \%)$ of abruptio placenta were between 30 to 35 years. Next most common age group were between 25 to 30 years (30\%). Least incidence was seen among the age group 20-25 years $(10 \%)$.

Table 2: Association with parity.

\begin{tabular}{|ll|}
\hline Parity & Percentage \\
\hline G1 & 15 \\
\hline G2 & 35 \\
\hline G3 & 30 \\
\hline G4,G5 & 20 \\
\hline
\end{tabular}


Maximum numbers of cases were gravida $2(35 \%) .15 \%$ patients were gravida $1.30 \%$ were third gravida and $20 \%$ were gravida $4^{\text {th }}$ and $5^{\text {th }}$

Table 3: Association with PIH.

\begin{tabular}{|ll|}
\hline Type & Percentage \\
\hline Severe preeclampsia & $75 \%$ \\
\hline eclampsia & $10 \%$ \\
\hline Normal BP & $15 \%$ \\
\hline
\end{tabular}

Patients who had severe preeclampsia have maximum rate of abruptio (75\%). Most of them were associated with anemia and PIH.10\% patients with eclampsia had abruptio placenta. Even normotensive groups had abruption which was about $15 \%$.

Table 4: Fetal outcome.

\begin{tabular}{|ll|}
\hline Birth & Percentage \\
\hline Still birth & $25 \%$ \\
\hline Live birth & $75 \%$ \\
\hline
\end{tabular}

$75 \%$ had live birth, $25 \%$ had still born baby. Among them 5 died in early neonatal period due to prematurity. Fetal complications included hypoxia, anemia, growth restriction, prematurity, neurodevelopmental problems, prematurity and fetal death.

Table 5: Maternal complications.

\begin{tabular}{|ll|}
\hline Complication & Percentage \\
\hline PPH & 30 \\
\hline DIC & 25 \\
\hline ARF & 13 \\
\hline Shock & 12 \\
\hline Infections & 10 \\
\hline Others & 10 \\
\hline
\end{tabular}

Maternal complications associated with abruption were postpartum haemorrhage (pph) (30\%), disseminated intravascular coagulation (dic) $(25 \%)$, acute renal failure (arf) (13\%), shock (12\%). 10\% patients had infections and $10 \%$ suffered from other complication.

\section{DISCUSSION}

Placental abruption is one of the serious complications of pregnancy, as it causes both poor maternal and fetal morbidity and mortality. The incidence of abruptio placenta was $1.6 \%$ in our study, which is somewhat near to study by Wasnik SK. ${ }^{4}$ The signs and symptoms of abruptio placenta vary depending upon the severity of bleeding and the degree of separation of the placenta. Abruption can occur at any trimester in pregnancy but mostly it occurs at 32-36 weeks of pregnancy. ${ }^{5}$ It was found that $75 \%$ of patients with severe preeclampsia, $10 \%$ of patients with eclampsia, $15 \%$ of patients with normal BP developed abruption in the study. Among the maternal complications, postpartum hemorrhage (PPH) was commonest followed by disseminated intravascular coagulation (DIC). PPH occurred in $30 \%$ of patients in the study, were as study by Talpur NN reported PPH in $28 \%$ of patients. ${ }^{6}$ DIC was associated with $25 \%$ of the patients in the study. Sher G observed DIC in $10-20 \%$ of his study patients with severe abruption and fetal demise which is comparable to the study. ${ }^{7}$ Renal failure is one of the major causes of maternal death. ${ }^{8}$ It was found that ARF is reported in $13 \%$ of the cases and shock in $12 \%$ were as study from Shrivatsava V reported $24.6 \%$ shock cases. ${ }^{9}$ Infection was found to be in $17.5 \%$ of patients in the study by Choudhary $\mathrm{V}$, in the study it is reported in $10 \%$ of the patients. ${ }^{10}$ Regarding fetal outcome, $75 \%$ were born alive and $25 \%$ were still births. A premature delivery can increase the fetal morbidity in cases of abruption. ${ }^{11-15}$ Routine antenatal check-up, treatment of anemia, timely referral to advanced centres and proper management with timely caesarean section, blood transfusion and good neonatal intensive care unit will further lower the perinatal and maternal morbidity and mortality.

\section{CONCLUSION}

Increasing age has been implicated as a predisposing factor in Abruptio placenta. Most of the patients were unbooked and incidence of abruptio was high in multiparous. The study reveals that severe preeclampsia increases incidence of abruptio. Mainly abruption was seen in term pregnancy. Majority of patients had associated anemia and PIH, and the mode of delivery varied according to maternal and fetal factors. Major complication on maternal side was PPH and fetal complications included hypoxia, anemia, growth restriction, prematurity, neurodevelopmental problems, prematurity and fetal death. Thus this study suggests that severe pre-eclampsia, eclampsia, high parity is independent risk factors for abruptio placenta. Antenatal care which identifies the risk factors like PIH plays an important role in decreasing the incidence of abruptio placenta and improving the maternal and fetal outcome. Regular antenatal checkup, anemia correction, early diagnosis and identification of gestational hypertension would prevent the maternal and perinatal morbidity and mortality. It should be managed in centres with advanced maternal and neonatal facilities. Though maternal morbidity can be reduced with modern management of abruptio placenta but timely diagnosis and intervention is necessary. Early detection and active management will reduce morbidity and mortality.

\section{ACKNOWLEDGMENTS}

Authors would like to thank Dr. Yashoda Mangal for his support during study.

Funding: No funding sources

Conflict of interest: None declared

Ethical approval: Not required 


\section{REFERENCES}

1. Workalemahu T, Enquobahrie DA, Gelaye B, Thornton TA, Tekola F, et al. Abruptio placentae risk and genetic variations in mitochondrial biogenesis and oxidative phosphorylation: replication of a candidate gene association study. Am J Obstet Gynecol. 2018;219(6):617.

2. Sylvester HC, Stringer M. Placental abruption leading to hysterectomy. BMJ. 2017;11:211-5.

3. Miller C, Grynspan D, Gaudet L, Ferretti E, Lawrence $\mathrm{S}$, et al. Maternal and neonatal characteristics of a Canadian urban cohort receiving treatment for opioid use disorder during pregnancy. J Dev Orig Health Dis. 2018;16:1-6.

4. Plowman RS, Javidan C, Raptis CA. Imaging of pregnancy-related vascular complications. Radiographics. 2017;37(4):1270-89.

5. Bibi S, Ghaffer S, Pir MA, Yousfani S. Risk factors and clinical outcome in placental abruption: a retrospective analysis. $\mathrm{J}$ Pak Medic Asso. 2009:59(10):672-4.

6. Talpur NN, Memon SR, Jamro B, Korejo R. Maternal and fetal morbidity with abruptio placentae. Rawal Med J. 2011;36(4):297-300.

7. Sher G. Pathogenesis and management of uterine inertia complicating abruptio placentae with consumption coagulopathy. Am J Obstet Gynecol. 1977;129:164-70.

8. Campbell S, Lee C. Disorders of placentation. Obstetrics. $17^{\text {th }}$ ed. Arnold London. 2002:171-3.
9. Shrivastava V, Kotur P, Jauhari A. Maternal and fetal outcome among abruptio placentae at a rural tertiary hospital in Karnataka, India: A Retrospective analysis. Int J Res Med Sci. 2014;2(4):1655-8.

10. Choudhary V. Rathi S, Somani S. Evaluation of risk factors and obstetric and perinatal outcome in abruptio placentae. 2015;14(5):36-9.

11. Humayun S, Nahid F. Comparison of pregnancy outcome among placenta praevia and abruption, Ann King Edward Med Coll. 2005;11(1):58-9.

12. Pitaphrom A, Sukcharoen N. Pregnancy outcome in placental abruption. J Med Assoc Thai. 2006;89(10):1572-8.

13. Sheiner E, Shoham-Vardi I, Hadar, Hallak M. Incidence, obstetric risk factors and pregnancy outcome of preterm placental abruption: a retrospective analysis. J Matern Fetal Neonatal Med. 2002;11(1):34-9.

14. Allred LS, Batton D. The effect of placental abruption on the short-term outcome of premature infants. Am J Perinatol. 2004:21(3):157-62.

15. Ananth CV, Getahun D, Peltier MR, Smulian JC. Placental abruption in term and preterm gestations: evidence for hetrogenicity in clinical pathways. Obstet Gynecol. 2006;107(4):785-92.

Cite this article as: Mishra R, Misra AP. Abruptio placenta and its maternal and fetal outcome. Int $\mathrm{J}$ Reprod Contracept Obstet Gynecol 2019;8:3323-6. 